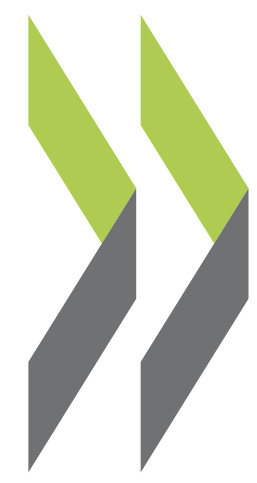

OECD Economics Department Working Papers No. 1524

Keeping track of global Jaime Martinez-Martin, trade in real time Elena Rusticelli 
10 December 2018

ECONOMICS DEPARTMENT

\section{KEEPING TRACK OF GLOBAL TRADE IN REAL TIME}

ECONOMICS DEPARTMENT WORKING PAPERS No. 1524

\section{By Jaime Martinez-Martin and Elena Rusticelli}

OECD Working Papers should not be reported as representing the official views of the OECD or of its member countries. The opinions expressed and arguments employed are those of the authors.

Authorised for publication by Luiz de Mello, Director, Policy Studies Branch, Economics Department.

All Economics Department Working Papers are available at www.oecd.org/eco/workingpapers.

JT03441083 
OECD Working Papers should not be reported as representing the official views of the OECD or of its member countries. The opinions expressed and arguments employed are those of the authors.

Working Papers describe preliminary results or research in progress by the author(s) and are published to stimulate discussion on a broad range of issues on which the OECD works.

Comments on Working Papers are welcomed, and may be sent to OECD Economics Department, 2 rue André Pascal, 75775 Paris Cedex 16, France, or by e-mail to eco.contact@oecd.org.

All Economics Department Working Papers are available at www.oecd.org/eco/workingpapers

This document and any map included herein are without prejudice to the status of or sovereignty over any territory, to the delimitation of international frontiers and boundaries and to the name of any territory, city or area.

The statistical data for Israel are supplied by and under the responsibility of the relevant Israeli authorities. The use of such data by the OECD is without prejudice to the status of the Golan Heights, East Jerusalem and Israeli settlements in the West Bank under the terms of international law.

On 3 May 2018, the OECD Council invited Lithuania to become a Member. At the time of publication the deposit of Lithuania's instrument of accession to the OECD Convention was pending and therefore Lithuania does not appear in the list of OECD Members and is not included in the OECD zone aggregates.

On 25 May 2018, the OECD Council invited Colombia to become a Member. At the time of publication the deposit of Colombia's instrument of accession to the OECD Convention was pending and therefore Colombia does not appear in the list of OECD Members and is not included in the OECD zone aggregates.

\section{(C) OECD (2018)}

You can copy, download or print OECD content for your own use, and you can include excerpts from OECD publications, databases and multimedia products in your own documents, presentations, blogs, websites and teaching materials, provided that suitable acknowledgment of OECD as source and copyright owner is given. All requests for commercial use and translation rights should be submitted to rights@oecd.org 


\section{ABSTRACT/RESUMÉ}

\section{Keeping track of global trade in real time}

This paper builds an innovative composite world trade cycle index (WTI) by means of a dynamic factor model to monitor and perform short-term forecasts in real time of world trade growth of both goods and (usually neglected) services. The selection of trade indicator series is made using a multidimensional approach, including Bayesian model averaging techniques, dynamic correlations and Granger non-causality tests in a linear VAR framework. To overcome real-time forecasting challenges, the dynamic factor model is extended to account for mixed frequencies, to deal with asynchronous data publication and to include hard and survey data along with leading indicators. Nonlinearities are addressed with a Markov switching model. Simulations analysis in pseudo real-time suggests that: i) the global trade index is a useful tool to track and forecast world trade in real time; ii) the model is able to infer global trade cycles precisely and better than the few competing alternatives; and iii) global trade finance conditions seem to lead the trade cycle, in line with the theoretical literature.

Keywords: Real-time forecasting, world trade, dynamic factor models, markov switching models, VAR models, cycles, leading indicators, granger non-causality, bayesian model averaging, goods trade, services trade

JEL Classification: E32, C22, E27

\section{Suivre l'évolution du commerce mondial en temps réel}

Cet article établit un indicateur composite innovant du cycle du commerce mondial (WTI) au moyen d'un modèle à facteurs dynamiques qui permet de surveiller et d'effectuer des prévisions à court terme en temps réel de la croissance du commerce mondial de biens et de services (généralement négligés). La sélection des séries d'indicateurs du commerce est effectuée à l'aide d'une approche multidimensionnelle comprenant des techniques de «Bayesian model averaging », des corrélations dynamiques et des tests d'absence de causalité de Granger dans un cadre de VAR linéaire. Pour surmonter les difficultés de prévision en temps réel, le modèle à facteurs dynamiques est étendu pour prendre en compte des fréquences mixtes, pour traiter la publication asynchrone de données et pour inclure des données de base et d'enquête ainsi que des indicateurs avancés. Les non-linéarités sont traitées avec un modèle de Markov à changement de régime. L'analyse des simulations en temps pseudo-réel suggère que: i) l'indicateur du commerce mondial est un outil utile pour suivre et prévoir le commerce mondial en temps réel; ii) le modèle est capable de déduire les cycles du commerce mondial avec précision et mieux que les quelques alternatives concurrentes; et iii) les conditions de financement du commerce mondial semblent mener le cycle du commerce, conformément à la littérature théorique.

Mots-clés : prévisions en temps réel, commerce mondial, modèles à facteurs dynamiques, modèle de markov à changement de régime, modèles VAR, cycles, indicateurs avancés, non-causalité de granger, bayesian model averaging, commerce de biens, commerce de services

Codes JEL : E32, C22, E27 


\section{Table of contents}

KEEPING TRACK OF GLOBAL TRADE IN REAL TIME ....................................................... 5

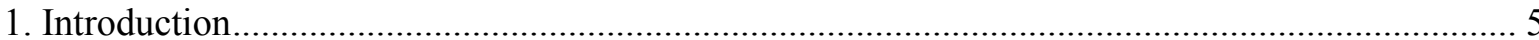

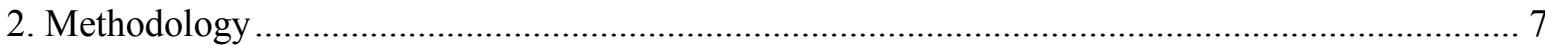

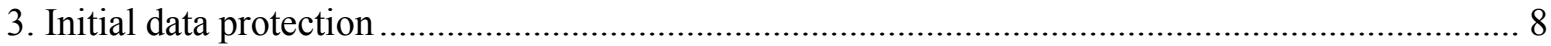

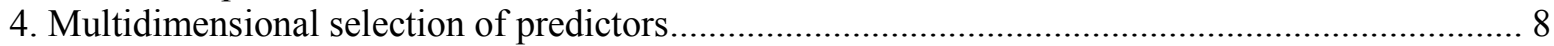

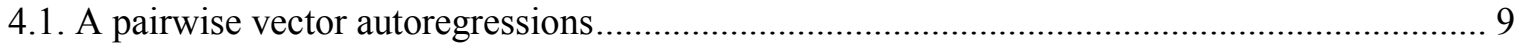

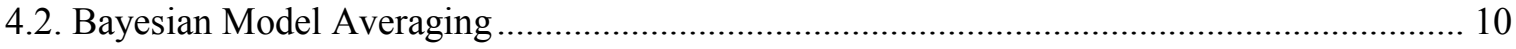

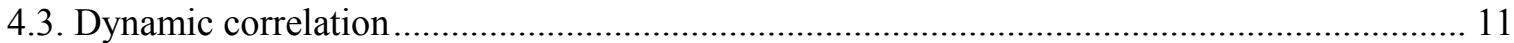

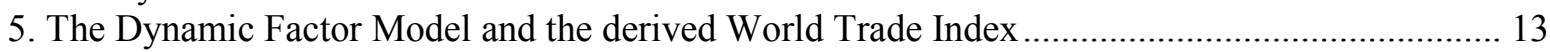

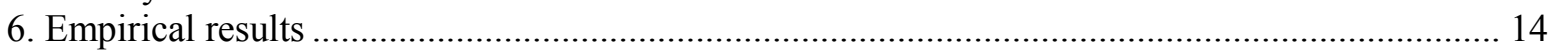

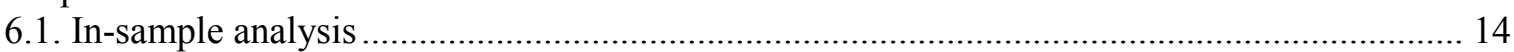

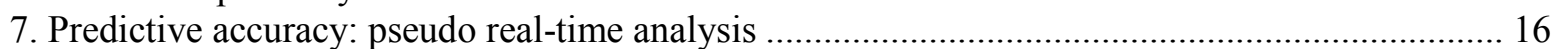

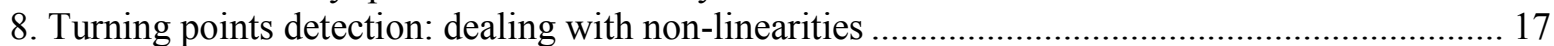

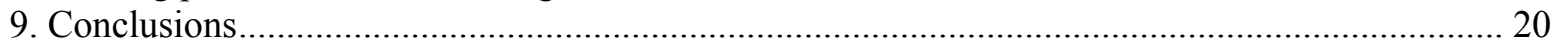

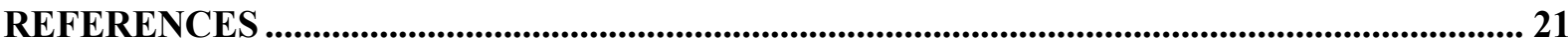

Annex A. State space representation and mixing data frequencies .................................................... 23

Annex B. Mixing frequencies............................................................................................................................ 26

\section{Tables}

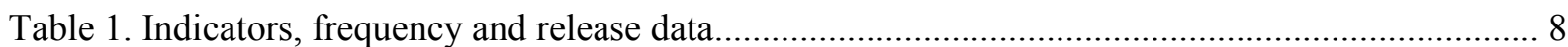

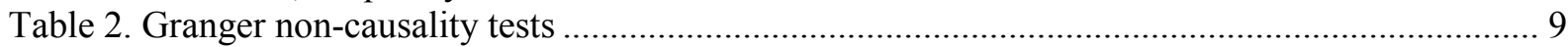

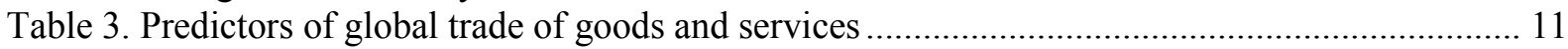

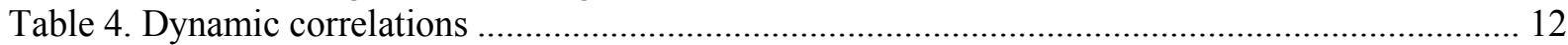

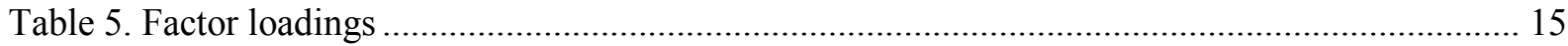

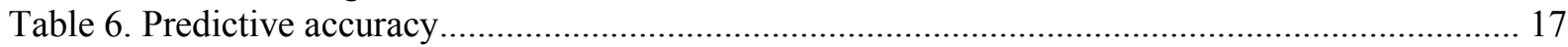

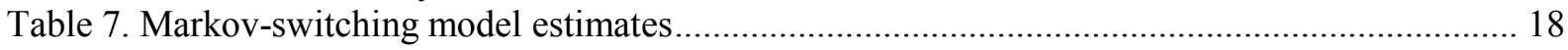

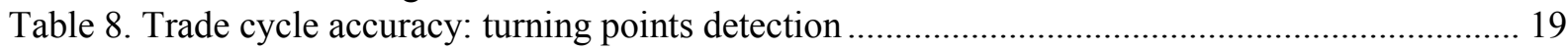

Figures

Figure 1. World trade growth (annual, 3-month MA) and recessions in the United States ................... 6

Figure 2. Kernel densities, services trade as a percentage of GDP ................................................ 7

Figure 3. Log likelihood and lead time of forward-looking indicators ............................................. 16

Figure 4. Probabilities of world trade growth contractions from the WTI ......................................... 20 


\title{
KEEPING TRACK OF GLOBAL TRADE IN REAL TIME
}

\author{
By \\ Jaime Martinez-Martin and Elena Rusticelli ${ }^{1}$
}

\section{Introduction}

1. The unexpectedly large plummet in trade flows in the aftermath of the Global Financial Crisis of 2008-09 (Martins and Araujo, 2009; Baldwin, 2009; Bussiére et al., 2013) highlighted the need for new tools able to accurately monitor trade developments in real time due to its strong association with growth. However, in times of uncertainty, when interest in predicting trade is the largest, projecting trade conditions on a higher frequency basis becomes extremely difficult. Indeed, tracking global trade in real time is challenging since trade data are published with a considerable lag given the large number of countries' input needed to compile an estimate of world trade. ${ }^{2}$

2. There is a small but growing literature on forecasting and leading indicators of international trade (Gregory et al., 1997; Burgert and Dees, 2008; Guichard and Rusticelli, 2011, Jakaitiene and Dees, 2012; Stratford, 2013; Golinelli and Parigi 2014; World Trade Organisation, 2016, Barhoumi et al., 2016). These papers select a limited number of time series as potential predictors and aggregate them into a composite indicator of the international trade cycle. However, most of the related literature usually focuses on merchandise trade only. For example, the World Trade Organization (2016) publishes an aggregate of several sub-indices based on export orders, international air freight, container shipping, automobile sales and production, electronic components and agricultural raw materials (Figure 1).

\footnotetext{
1 The authors are senior economist from the European Central Bank and at Banco de España (email: jaime.martinez-martin@ecb.europa.eu) and economist from Economics Department of the OECD (email: elena.rusticelli@oecd.org), respectively. The opinions expressed and arguments employed are those of the authors and should not be reported as representing the official views of the OECD, ECB and Banco de España. We would like to thank Juan Carlos Berganza, Ángel Estrada, Ignacio Hernando, Pilar L'Hotellerie (Banco de España), Francis X. Diebold, Jesús Fernández-Villaverde (University of Pennsylvania), Robert Koopman and Coleman Nee (WTO), Alessandro Maravalle and David Haugh for their helpful comments. We are very grateful to Alberto F. Borrallo and Marina Conesa for their excellent research assistance and Véronica Humi for editorial assistance.

${ }^{2}$ For example, in August 2017 the most up-to-date information on trade of goods and services provided by the OECD was from Q1 2017. The OECD publishes a quarterly index of world trade based on national accounts with a one-quarter lag.
} 
Figure 1. World trade growth (annual, 3-month MA) and recessions in the United States

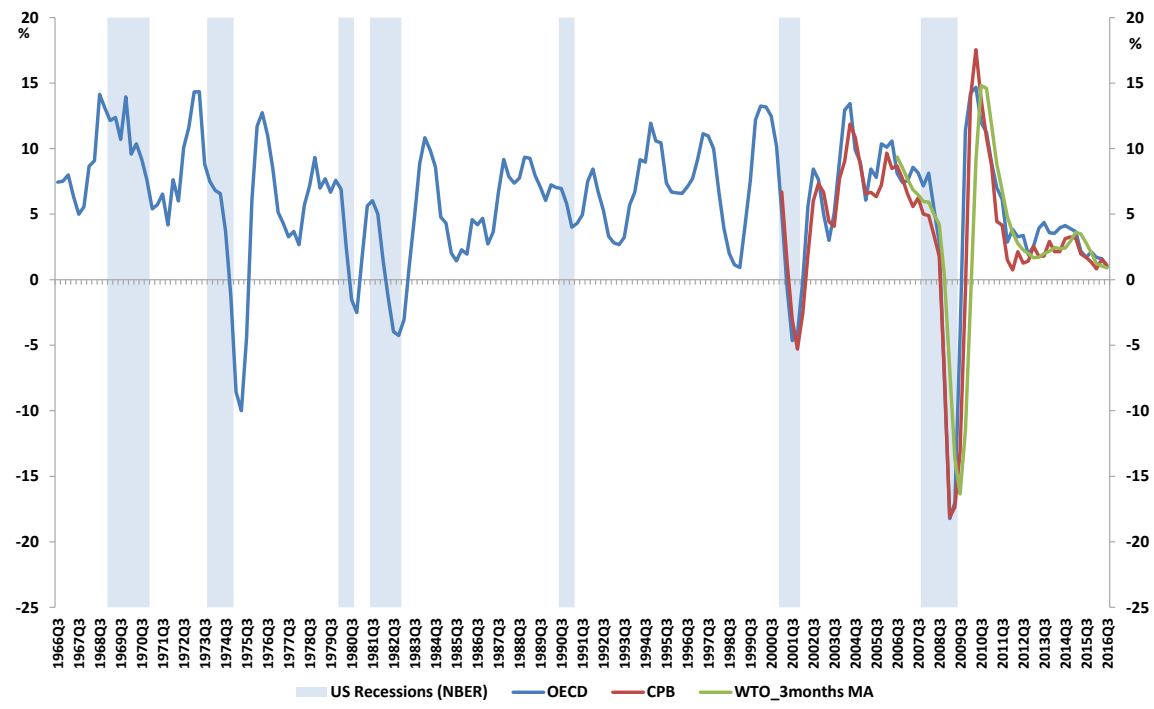

Note: Shaded areas refer to US recessions as dated by the NBER. CPB and WTO refer to merchandise volumes, while OECD includes also services.

Source: OECD, CPB, WTO, and NBER.

3. The contribution of this paper is to test the usefulness of a small-scale Dynamic Factor Model (DFM), which accounts for mixed frequencies and deals with asynchronous data publication, for predicting international trade cycles in real time. In contrast with most of the existing literature, the model accounts for both goods and services trade. Predicting services trade is becoming increasingly important because of its growing share in world trade across countries. According to the World Bank database, the ratio of services to world GDP has gradually increased from $8 \%$ in the nineties to $13 \%$ in 2015 . Moreover, empirical evidence suggests that this trend is not only valid at the aggregate level but also on a single country basis (Figure 2$)^{3}$

\footnotetext{
${ }^{3}$ Further evidence is provided by Timmer et al. (2016) by exploiting the more recent World Input-Output Database (WIOD).
} 
Figure 2. Kernel densities, services trade as a percentage of GDP

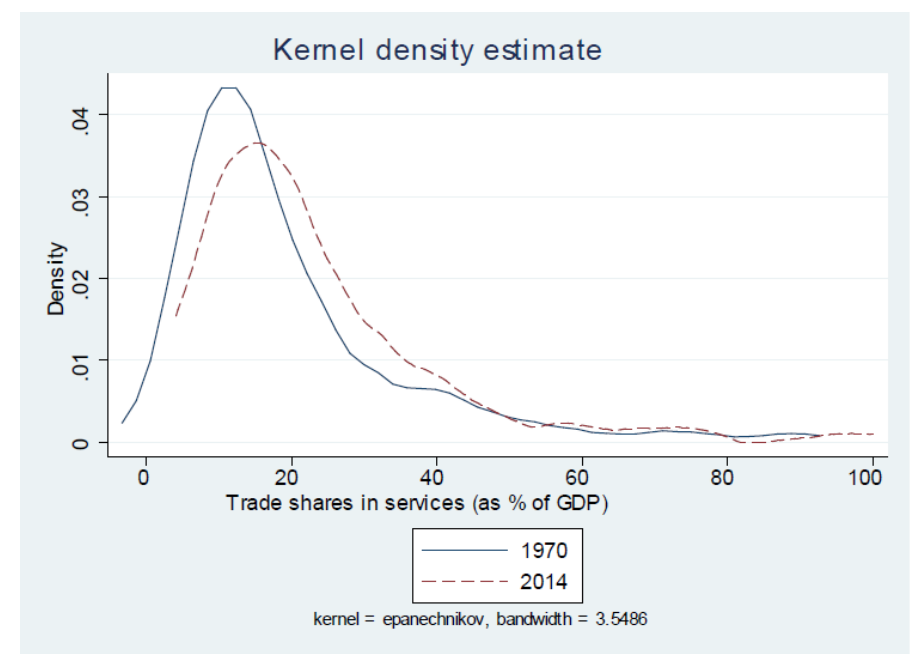

Source: The World Bank Database (217 countries).

4. The structure of the paper is organised as follows: the next section contains the data description and the criteria for selecting the predictor series used in the DFM. The selection is made using a multidimensional approach based on Bayesian model averaging techniques, dynamic correlations and Granger non-causality tests in a linear VAR framework. Section 2 also describes the DFM underlying the World Trade Index (WTI) to monitor global trade growth and to capture trade cycle turning points. Section 3 presents the main empirical results from in-sample and out-of-sample simulations. The forecasting accuracy of the WTI is compared with several standard alternatives and is carried out through a pseudo real-time analysis: the data vintages are constructed by taking into account the lag of synchronicity in data publication that characterises real-time data flow. Section 4 concludes and proposes several future lines of research.

5. The main results are the following. First, the WTI explains more than $92 \%$ of the variance of world trade growth of goods and services, pointing to a high explanatory power of this small-scale dynamic factor model for world trade growth. Second, the pseudo realtime analysis shows that this DFM clearly outperforms univariate forecasts, especially when forecasting the next unavailable figure of trade growth. This confirms that monthly real and survey data provide useful information to forecast current world trade growth. Finally, the in-sample analysis highlights that global credit and trade finance conditions is a significant leading indicator of the world trade cycle in the recent past, in line with the literature.

\section{Methodology}

6. The DFM is built and tested in three main steps: (i) initial data selection based on the literature; (ii) selection of the subset of indicators to be used in the composite index; (iii) estimation of the DFM and construction of the WTI. 


\section{Initial data protection}

7. The data employed in this paper span the period from 1967 to 2016 (Table 1). ${ }^{4}$ Thirty potential predictor series are considered on the basis of their good forecasting performance as indicated in the literature (Guichard and Rusticelli, 2011; and Barhoumi and Ferrara, 2016).

Table 1. Indicators, frequency and release data

\begin{tabular}{|c|c|c|c|c|c|}
\hline & & Start date & Lags & Freq & Source \\
\hline & Merchandise world trade & 1968 & 2 & $\mathrm{M}$ & CPB \\
\hline & World trade of goods and services & 1966 & 3 & $\mathrm{Q}$ & OECD \\
\hline 1 & Commodity Research Bureau index & 1991 & 1 & $\mathrm{M}$ & CRB \\
\hline 2 & Brent - Oil prices & 1957 & 1 & M & Thomson Reuters \\
\hline 3 & USD Nominal Effective Exchange Rate & 1963 & 1 & M & BIS \\
\hline 4 & Baltic Dry Index & 1985 & 1 & M & The Baltic Exchange \\
\hline 5 & IFO Climate & 1991 & 1 & M & IFO \\
\hline 6 & IFO Expectation & 1991 & 1 & M & IFO \\
\hline 7 & Global PMI (Manufacturing \& Services) & 1998 & 1 & M & Markit Economics \\
\hline 8 & World industrial production index & 1991 & 2 & M & $\mathrm{CPB}$ \\
\hline 9 & OECD Retail sales & 2000 & 3 & M & OECD \\
\hline 10 & World steel production & 1980 & 1 & M & IISI \\
\hline 11 & Harper shipping index & 1996 & 1 & M & Harper Petersen \& Co. \\
\hline 12 & International air freight traffic & 1996 & 1 & M & IATA \\
\hline 13 & Tech pulse index & 1971 & 1 & M & CSIP \\
\hline 14 & World semiconductor billings & 1976 & 2 & M & SIA \\
\hline 15 & Global PMI new orders & 1998 & 1 & M & Markit Economics \\
\hline 16 & Global PMI new export orders & 1998 & 1 & M & Markit Economics \\
\hline 17 & Global PMI Manufacturing index & 1998 & 1 & M & Markit Economics \\
\hline 18 & Global PMI stock level index & 1998 & 1 & M & Markit Economics \\
\hline 19 & $\mathrm{OECD}+\mathrm{BRICS} \mathrm{CLI}$ & 1960 & 2 & M & OECD \\
\hline 20 & World stock market prices index & 1973 & 1 & M & Datastream \\
\hline 21 & USA IPI & 1991 & 2 & M & CPB \\
\hline 22 & Japan IPI & 1991 & 2 & M & CPB \\
\hline 23 & EuroArea IPI & 1991 & 2 & M & CPB \\
\hline 24 & Adv. Economies IPI & 1991 & 2 & M & CPB \\
\hline 25 & Emerging Economies IPI & 1991 & 2 & M & CPB \\
\hline 26 & Asia IPI & 1991 & 2 & M & CPB \\
\hline 27 & LatinAmerican IPI & 1991 & 2 & M & CPB \\
\hline 28 & Central and Eastern IPI & 1991 & 2 & M & CPB \\
\hline 29 & Africa and MENA IPI & 1991 & 2 & M & $\mathrm{CPB}$ \\
\hline 30 & US high yield spread & 1984 & 1 & $\mathrm{M}$ & BdE calculations \\
\hline
\end{tabular}

\section{Multidimensional selection of predictors}

8. Given the plethora of all available time series, possibly correlated with world trade, the selection of predictors is a crucial step in the construction of dynamic factor models. Boivin and $\mathrm{Ng}$ (2006) found evidence that selecting a smaller subset of potential indicators improves substantially the forecast performance. Thus, we select a subset of world trade predictors among the initial thirty series using three different methods: pairwise vector autoregressions, Bayesian model averaging and dynamic correlations.

\footnotetext{
${ }^{4}$ Stationarity has been established by transforming monthly indicators into month-on-month growth rates.
} 


\subsection{A pairwise vector autoregressions}

9. Linear vector autoregressions (VARs) are estimated to investigate the predictive ability of the selected indicators. To this end, Granger non-causality tests are run on the growth rate of world trade of goods and services. Bivariate vector autoregressive models (the lag order is fixed according to AIC criteria) for each indicator and the associated marginal significance levels are estimated to assess their predictability. ${ }^{5}$ The $p$-values of the Wald tests of Granger non-causality are reported over the evaluation period January 1967 - September 2016 (Table 2). ${ }^{6}$

Table 2. Granger non-causality tests

\begin{tabular}{|c|c|c|}
\hline \multicolumn{2}{|c|}{ Predictors } & \multirow{2}{*}{$\frac{\text { p-values }}{0.00}$} \\
\hline 1 & CRB index & \\
\hline 2 & Brent - Oil prices & 0.00 \\
\hline 3 & USD NEER & 0.15 \\
\hline 4 & Baltic Dry Index & 0.00 \\
\hline 5 & IFO Climate & 0.00 \\
\hline 6 & IFO Expectation & 0.00 \\
\hline 7 & Global PMI (Manufacuring \& Services) & 0.00 \\
\hline 8 & World IPI & 0.37 \\
\hline 9 & OECD Retail sales & 0.02 \\
\hline 10 & World steel production & 0.40 \\
\hline 11 & Harper shipping index & 0.00 \\
\hline 12 & International air freight traffic & 0.91 \\
\hline 13 & Tech pulse index & 0.00 \\
\hline 14 & World semiconductor billings & 0.32 \\
\hline 15 & Global PMI new orders & 0.00 \\
\hline 16 & Global PMI new export orders & 0.00 \\
\hline 17 & Global PMI Manufacturing index & 0.00 \\
\hline 18 & Global PMI stock level index & 0.08 \\
\hline 19 & OECD+ BRICS CLI & 0.00 \\
\hline 20 & World stock market prices index & 0.00 \\
\hline 21 & USA IPI & 0.00 \\
\hline 22 & Japan IPI & 0.03 \\
\hline 23 & EuroArea IPI & 0.20 \\
\hline 24 & Adv. Economies IPI & 0.15 \\
\hline 25 & Emerging Economies IPI & 0.00 \\
\hline 26 & Asia IPI & 0.43 \\
\hline 27 & LatinAmerican IPI & 0.58 \\
\hline 28 & Central and Eastern IPI & 0.90 \\
\hline 29 & Africa and MENA IPI & 0.09 \\
\hline 30 & US high yield spread & 0.00 \\
\hline
\end{tabular}

Note: $p$-values for Wald tests of Granger non-causality tests based on heteroskedasticity-robust variance estimator. The null hypothesis of Ganger non-causality is rejected at the $90 \%, 95 \%$ and $99 \%$ confidence levels in case of p-values lower than $0.10,0.05$ and 0.01 respectively.

Source: Authors' calculation.

\footnotetext{
${ }^{5}$ In the absence of structural breaks, the existence of predictability in the population is a necessary precondition for outof-sample forecastability (see Inoue and Kilian, 2004).

${ }^{6}$ In some cases, one needs to consider the possibility of cointegration in levels. In those cases, all rejections remain significant if we follow Dolado and Lütkepol (1996) in conducting a lag-augmented Granger non-causality test.
} 
10. The results from the pairwise VARs suggest that some soft indicators (i.e., IFO surveys and PMIs) are highly statistically significant predictors of the growth rate of world trade of goods and services. In contrast, the evidence of predictability is weaker for geographical industrial production indices and neither steel production nor world semiconductor billings have significant predictive power. This does not necessarily mean that all bilateral covariates lack predictive power. The explanation presumably is that some of them are forward-looking and embody information about future movements in world trade of goods and services that cannot easily be captured by alternative means.

\subsection{Bayesian Model Averaging}

11. Bayesian Model Averaging (BMA) techniques, based on Hoeting et al. (1999), are applied to assign a weight to each variable included in an "optimal" model accurately selected among all possible regressors combinations to explain world trade growth variations. $^{7}$

12. The posterior distribution of the quarterly world trade growth, WT, given the dataset $\mathrm{D}$ is defined as:

$\operatorname{pr}(W T / D)=\sum_{k=1}^{K} \operatorname{pr}\left(W T / M_{k}, D\right) \operatorname{pr}\left(M_{k} / D\right)$

The probability in (1) is computed as an average of the posterior distributions under each of the $M_{1}, \ldots, M_{k}$ models under consideration. The weight is represented by the posterior probability of each model $M_{k}$ given by:

$\operatorname{pr}\left(M_{k} / D\right)=\frac{\operatorname{pr}\left(D / M_{k}\right) \operatorname{pr}\left(M_{k}\right)}{\sum_{l=1}^{K} \operatorname{pr}\left(D / M_{l}\right) \operatorname{pr}\left(M_{l}\right)}$

where $\operatorname{pr}\left(D / M_{k}\right)=\int \operatorname{pr}\left(D / \theta_{k}, M_{k}\right) \operatorname{pr}\left(\theta_{k} / M_{k}\right) c d \theta_{k}$ is the integrated likelihood of $M_{k}$ and $\theta_{k}$ is its set of parameters.

13. It assumes that the posterior distribution is proportional to the marginal probability by the prior probability assigned to each model, in this case, a uniform variable. The result gives the cumulative model probabilities of the predictor's selection based on the whole spectrum of model combinations. Given a prior inclusion probability of $50 \%$, the chosen threshold for the variable selection in the model is that the posterior inclusion probability (PIP) should be above $50 \%$.

14. The entire model space is fully explored by iterating all possible regressor combinations (i.e. $2^{\mathrm{k}}$ iterations, where $k=30$ is the number of covariates). The results suggest that soft indicators such as global PMI new orders and manufacturing indices along with IFO Expectation and Climate surveys contain significant information (Table 3). Hard indicators such as global and the US industrial production indices and world semiconductor billings ought to be included with higher probability. Finally, a financial (leading) predictor such as the US high yield spread may be also considered.

\footnotetext{
${ }^{7}$ For an overview of model averaging methods in the field of economics see Moral-Benito (2015).
} 
Table 3. Predictors of global trade of goods and services

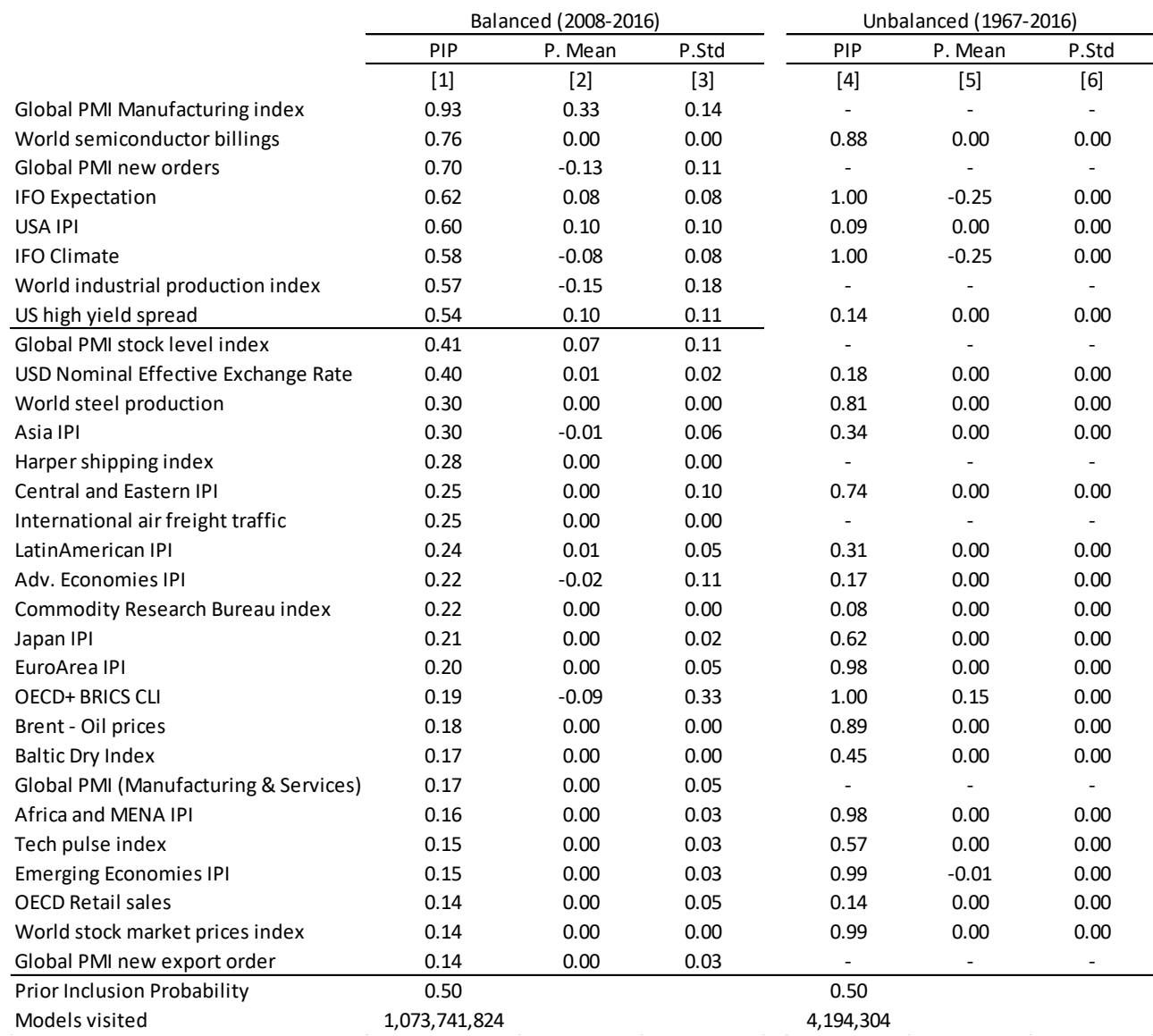

Note: PIP refers to the posterior inclusion probability of a particular predictor. Given the prior inclusion probability is equal for all the variables (i.e., 0.5), those regressors with PIP above 0.5 are considered as robust drivers of global trade growth; P. Mean refers to the posterior mean conditional on inclusion of a given regressor in the empirical model, which is a weighted average of model-specific coefficient estimates with weights given by the model-specific R2; P. Std. refers to the posterior standard deviation, which is a weighted average of model-specific standard deviations.

Source: Authors' calculation.

\subsection{Dynamic correlation}

15. The third approach to data selection focuses on those predictors that exhibit high statistical dynamic correlation with the quarterly OECD world trade growth rate, which is the target series to be monitored. ${ }^{8}$

16. To test the forward-looking ability of those predictors that have already shown predictability content by means of Granger non-causality tests and Bayesian averaging techniques, pair-wise dynamic correlations (both lagging and leading) are computed. As expected, soft indicators lead world trade growth, in particular the global PMI new export

\footnotetext{
${ }^{8}$ Dynamic correlations are commonly used in this context since they become the best alternative to static analysis for them to capture the co-movement between predictors (Croux et al. 2001).
} 
orders index (Table 4). Plus, it is worth mentioning the inverse (leading) relationship of the US high yield spread with the reference series.

Table 4. Dynamic correlations

\begin{tabular}{|c|c|c|c|c|c|c|c|}
\hline & $\mathbf{Y}$ & $\mathbf{Y}_{\mathrm{t}-1}$ & $Y_{t-2}$ & $\mathbf{Y}_{\mathrm{t}-\mathbf{3}}$ & $Y_{t+1}$ & $\mathbf{Y}_{\mathrm{t}+2}$ & $Y_{t+3}$ \\
\hline & [1] & [2] & [3] & [4] & [5] & [6] & [7] \\
\hline 1 CRB index & 0.07 & 0.09 & 0.10 & 0.10 & 0.03 & -0.01 & -0.08 \\
\hline 2 Brent - Oil prices & 0.07 & 0.10 & 0.10 & 0.10 & 0.04 & -0.01 & -0.09 \\
\hline 3 USD NEER & -0.17 & -0.18 & -0.18 & -0.17 & -0.15 & -0.11 & -0.07 \\
\hline 4 Baltic Dry Index & 0.25 & 0.26 & 0.26 & 0.25 & 0.23 & 0.19 & 0.12 \\
\hline 5 IFO Climate & 0.43 & 0.47 & 0.48 & 0.48 & 0.37 & 0.28 & 0.19 \\
\hline 6 IFO Expectation & 0.75 & 0.72 & 0.67 & 0.58 & 0.73 & 0.68 & 0.59 \\
\hline 7 Global PMI (Manufacturing \& Services) & 0.83 & 0.78 & 0.71 & 0.61 & 0.83 & 0.79 & 0.71 \\
\hline 8 World IPI & 0.03 & 0.05 & 0.07 & 0.09 & 0.00 & -0.05 & -0.11 \\
\hline 9 OECD Retail sales & 0.06 & 0.07 & 0.08 & 0.08 & 0.04 & 0.00 & -0.04 \\
\hline 10 World steel production & 0.10 & 0.10 & 0.09 & 0.07 & 0.08 & 0.04 & -0.01 \\
\hline 11 Harper shipping index & 0.30 & 0.34 & 0.38 & 0.41 & 0.25 & 0.20 & 0.15 \\
\hline 12 International air freight traffic & 0.36 & 0.41 & 0.43 & 0.44 & 0.29 & 0.19 & 0.08 \\
\hline 13 Tech pulse index & 0.05 & 0.12 & 0.18 & 0.23 & -0.02 & -0.10 & -0.17 \\
\hline 14 World semiconductor billings & 0.29 & 0.39 & 0.47 & 0.53 & 0.19 & 0.09 & 0.00 \\
\hline 15 Global PMI new orders & 0.82 & 0.76 & 0.68 & 0.58 & 0.83 & 0.79 & 0.72 \\
\hline 16 Global PMI new export orders & 0.89 & 0.82 & 0.72 & 0.60 & 0.91 & 0.86 & 0.75 \\
\hline 17 Global PMI Manufacturing index & 0.89 & 0.83 & 0.74 & 0.63 & 0.89 & 0.84 & 0.74 \\
\hline 18 Global PMl stock level index & 0.58 & 0.66 & 0.71 & 0.73 & 0.48 & 0.37 & 0.24 \\
\hline 19 OECD+ BRICS CLI & 0.75 & 0.76 & 0.75 & 0.70 & 0.70 & 0.62 & 0.52 \\
\hline 20 World stock market prices index & 0.14 & 0.15 & 0.16 & 0.16 & 0.10 & 0.06 & -0.01 \\
\hline 21 USA IPI & 0.16 & 0.22 & 0.27 & 0.30 & 0.08 & 0.01 & -0.08 \\
\hline 22 Japan IPI & 0.47 & 0.53 & 0.58 & 0.59 & 0.37 & 0.24 & 0.10 \\
\hline 23 EuroArea IPI & 0.27 & 0.35 & 0.40 & 0.44 & 0.16 & 0.03 & -0.10 \\
\hline 24 Adv. Economies IPI & 0.27 & 0.34 & 0.40 & 0.43 & 0.17 & 0.06 & -0.07 \\
\hline 25 Emerging Economies IPI & 0.07 & 0.08 & 0.09 & 0.09 & 0.04 & 0.00 & -0.06 \\
\hline 26 Asia IPI & -0.08 & -0.08 & -0.08 & -0.08 & -0.09 & -0.10 & -0.12 \\
\hline 27 LatinAmerican IPI & 0.05 & 0.07 & 0.09 & 0.09 & 0.01 & -0.04 & -0.09 \\
\hline 28 Central and Eastern IPI & -0.06 & -0.06 & -0.06 & -0.06 & -0.07 & -0.09 & -0.12 \\
\hline 29 Africa and MENA IPI & 0.02 & 0.05 & 0.08 & 0.10 & -0.02 & -0.08 & -0.13 \\
\hline 30 US high yield spread & -0.69 & -0.64 & -0.58 & -0.51 & -0.71 & -0.68 & -0.61 \\
\hline
\end{tabular}

Note: Highlighted cells refer to correlations between quarterly trade growth and predictors (leads/lags) higher than 0.7 .

Source: Authors' calculation.

17. Overall, the merged results of the three above-mentioned methods for predictor's selection suggest that only 9 out of 30 indicators contain significant predictive power. The selected drivers of global trade cover different dimensions, from hard to soft indicators: (i) global merchandise trade, world semiconductor billings, industrial production from the US and worldwide; and (ii) global PMIs such as manufacturing, new export orders, and IFOs expectations and climate surveys. Moreover, the US High Yield Spread, computed as the difference between the U.S. Corporate High Yield USD and the US 10 year Treasury Bond, has been also selected as proxy for the risk premium paid by risky borrowers. It should capture both the global impact of credit conditions on activity as well as via global trade finance conditions (Guichard and Rusticelli, 2011). ${ }^{9}$

\footnotetext{
${ }^{9}$ This choice is justified by the strong international correlation of international bonds spreads. Nonetheless, as a proxy for trade finance conditions, it underestimates the impact on trade if financial crises tend to restrict trade finance relatively more than other forms of credit. This may occur, for example, if international trade is more vulnerable to counterparty risks.
} 
18. Given the reduced set of monthly indicators selected, a rather small-scale DFM with coincident and leading indicators emerges as the most suitable methodological approach to generate a global trade cycle index such as the World Trade Index (WTI).

\section{The Dynamic Factor Model and the derived World Trade Index}

19. The dynamic properties of the DFM follow the lines proposed by Aruoba and Diebold (2010), who extended the single-index dynamic factor model suggested by Stock and Watson (1991). The main methodological advantages of this new linear dynamic factor model with respect to the previous literature are that: it can incorporate information from different series regardless of frequency and publication dates; it converts the information contained in the macroeconomic indicators (also leading) into inferences of the state of the global trade cycle. Hence, it is possible to create a global trade index, which is very easy to interpret and can be timely and automatically updated.

20. The original DFM was initially designed to deal with balanced panels of business cycle indicators so it could not handle the typical problems of the day-to-day monitoring of macroeconomic activity: mixed frequencies and ragged ends. To overcome such limitations, Camacho and Martinez-Martin (2014) show how to adapt DFMs to allow for any business cycle coincident (and leading) economic indicator regardless of publication delays and frequency (based on Stock and Watson, 1991; Mariano and Murasawa, 2003; and Aruoba and Diebold, 2010). On the basis of these techniques, the procedure underlying the WTI deals with missing observations by using Kalman filtering (Annex 1). ${ }^{10}$

21. Let us assume that the predictors included in the model admit a dynamic factor representation. In this case, each predictor can be written as the sum of two orthogonal components: an unobservable component that is common across predictors, $x_{t}$, which represents the overall trade cycle conditions, and an idiosyncratic component, which refers to the particular dynamics of the series. The WTI is then given by:

$x_{t}=d_{1}^{x} x_{t-1}+\cdots+d_{p 1}^{x} x_{t-p 1}+\varepsilon_{t}^{x}$

where the common component (latent trade cycle conditions) is assumed to evolve with autoregressive dynamics $A R(p l)$ and the errors are given by $\varepsilon_{t}^{x} \sim \operatorname{iidN}\left(0, \sigma_{x}^{2}\right)$.

22. In addition to building a monthly index that accurately captures trade cycle conditions, the model should be able to compute accurate short-term forecasts of quarterly world trade growth. To this purpose, let us consider $k_{1}$ quarterly indicators $g_{t}$ and $k_{2}$ monthly indicators $z_{t}$. For each of the quarterly indicators $g_{t}$, we assume that the evolution of its underlying monthly growth rates $g_{t}^{*}$ depends linearly on $x_{t}$ and on the idiosyncratic dynamics $u_{t}^{g}$, which evolve as an autoregressive process $A R\left(p_{2}\right)$ :

$g_{t}^{*}=\beta_{g} x_{t}+u_{t}^{g}$

$u_{t}^{g}=d_{1}^{g} u_{t-1}^{g}+\cdots+d_{p 2}^{g} u_{t-p 2}^{g}+\varepsilon_{t}^{g}$

where $\varepsilon_{t}^{g} \sim \operatorname{iidN}\left(0, \sigma_{g}^{2}\right)$.

\footnotetext{
${ }^{10}$ Missing observations are replaced by random draws from a variable whose distribution cannot depend on the parameters space that characterises the Kalman filter. The corresponding row is then skipped in the Kalman recursion and the measurement equation for the missing observation is set to the random choice.
} 
In addition, the evolution of each of the monthly indicators $z_{t}$ depends linearly on $x_{t}$ and on the idiosyncratic component and its dynamics can be expressed in terms of autoregressive processes of $p_{3}$ orders:

$z_{t}=\beta_{z} x_{t}+u_{t}^{z}$

$u_{t}^{Z}=d_{1}^{Z} u_{t-1}^{Z}+\cdots+d_{p 3}^{Z} u_{t-p 3}^{Z}+\varepsilon_{t}^{Z}$

where $\varepsilon_{t}^{z} \sim \operatorname{iidN}\left(0, \sigma_{z}^{2}\right)$.

23. Finally, the errors of the common component and of all idiosyncratic components are assumed to be mutually uncorrelated in cross-section and time-series dimensions. ${ }^{11}$ Using the assumptions described above, this model can be written in State-Space form and estimated by means of Kalman filtering (Annex 1).

\section{Empirical results}

\subsection{In-sample analysis}

24. Following the multidimensional approach in section 2.2, a first subset of nine predictors of global trade growth was selected on the basis of their higher predictive power. However, this was reduced to eight as the dynamic factor model estimation indicated that the world semiconductor index does not improve substantially the percentage of the variance of world trade growth explained by the WTI. It also does not exhibit a statistically significant factor loading based on the selection criteria of Camacho and Perez-Quirós (2010). More precisely, the information conveyed by the predictor is assumed to be mainly idiosyncratic and therefore it is not included in the final model.

25. The in-sample results from the dynamic factor model sequentially estimated from 1991 to 2017 clearly point to two types of world trade predictors: (i) a first subset of indicators, mainly coincident predictors, which exhibit short publication delays; and (ii) a second subset including potential leading indicators. To ensure the stationarity of the World Trade Index, soft indicators enter the model in levels whereas all other predictors are taken as month-on-month growth rates. ${ }^{12}$

\footnotetext{
${ }^{11}$ We could consider time-varying parameters. However, it is out of the scope of this paper and is left for further research.

12 In line with Mariano and Murasawa (2003), the quarterly growth rate of world trade is also included in the model as it adds information on synchronized co-movements to the construction of the single World Trade Index.
} 
Table 5. Factor loadings

\begin{tabular}{|c|c|c|c|c|c|c|c|c|c|c|}
\hline \multirow[b]{2}{*}{ Model } & \multicolumn{10}{|l|}{ Predictors } \\
\hline & WT & PMIman & US IPI & IFOex & IFOclim & World IPI & WT (CPB) & US spread & PMlex & (\% WT growth) \\
\hline \multirow[t]{2}{*}{ M1 } & 0.04 & 0.13 & 0.08 & 0.11 & . & & . & . & . & 48.6 \\
\hline & $(0.00)$ & $(-0.02)$ & $(-0.01)$ & $(-0.02)$ & . & & . & . & . & \\
\hline \multirow[t]{2}{*}{ M2 } & 0.05 & 0.12 & 0.09 & 0.22 & 0.15 & & . & . & . & 51.2 \\
\hline & $(0.00)$ & $(-0.01)$ & $(-0.01)$ & $(-0.01)$ & $(0.00)$ & & . & . & . & \\
\hline \multirow[t]{2}{*}{ M3 } & 0.05 & 0.12 & 0.10 & 0.22 & 0.15 & 0.12 & . & . & . & 55.9 \\
\hline & $(0.00)$ & $(-0.02)$ & $(-0.01)$ & $(-0.01)$ & $(0.00)$ & $(-0.02)$ & . & . & . & \\
\hline \multirow[t]{2}{*}{ M4 } & 0.05 & 0.13 & 0.10 & 0.22 & 0.15 & 0.12 & 0.09 & . & . & 62.3 \\
\hline & $(0.00)$ & $(-0.01)$ & $(-0.01)$ & $(-0.01)$ & $(0.00)$ & $(-0.02)$ & $(-0.01)$ & . & . & \\
\hline \multirow[t]{2}{*}{ M5 } & 0.05 & 0.13 & 0.10 & 0.22 & 0.15 & 0.12 & 0.09 & -0.07 & . & 77.9 \\
\hline & $(0.00)$ & $(-0.02)$ & $(-0.01)$ & $(-0.01)$ & $(0.00)$ & $(-0.02)$ & $(-0.01)$ & $(-0.01)$ & . & \\
\hline M6 & $\begin{array}{c}0.07 \\
(0.00)\end{array}$ & $\begin{array}{c}0.16 \\
(-0.02)\end{array}$ & $\begin{array}{c}0.12 \\
(-0.01)\end{array}$ & $\begin{array}{c}0.18 \\
(-0.01)\end{array}$ & $\begin{array}{c}0.12 \\
(-0.01)\end{array}$ & $\begin{array}{c}0.14 \\
(-0.01)\end{array}$ & $\begin{array}{c}0.11 \\
(-0.01)\end{array}$ & $\begin{array}{c}-0.09 \\
(-0.01)\end{array}$ & $\begin{array}{c}0.18 \\
(-0.02)\end{array}$ & 92.1 \\
\hline
\end{tabular}

Note: Entries refer to factor loadings estimates by maximum likelihood. They measure the correlation between the common factor and each of the indicators (in columns). Standard errors are in brackets. WT indicates quarterly world trade growth; PMIman indicates global PMIs manufacturing; PMIex indicates PMI new export orders, IFOex indicates IFOs expectations; IFOclim indicate IFO climate surveys; US IPI indicates US industrial production index; Wold IPI indicates world industrial production index; WT (CPB) indicates merchandise world trade growth; US spread indicates the US High Yield Spread.

Source: Authors' calculation.

26. The estimated coefficients of the factor loadings, which reflect the linkage of each observable with the latent factor, are statistically significant ${ }^{13}$ and show the expected sign (Table 5). The percentage of the variance of world trade growth explained by the model containing only coincident indicators (i.e. M4) is $62 \%$. The remaining two indicators, i.e. the US high yield spread and PMI new export orders index, are leading indicators anticipating world trade cycle dynamics in $h$ months, with $h=0,1,2,3 \ldots, .12 .{ }^{14}$ Both indicators exhibit coherent and statistically significant factor loadings and their inclusions increases the variance of global trade growth explained by the common factor up to $92 \%$ (Table 5).

27. In order to select an optimal number of leads, the log-likelihood values associated with these lead times are computed and plotted in Figure 3. The empirical simulations show that the likelihood function reaches its maximum when treating the PMI new export orders index as a coincident indicator of the common factor rather than a leading indicator (i.e. it leads the common factor by $h=0$ months). On the contrary, the US high yield spread leads the common factor by $h=1$ months.

\footnotetext{
13 To simplify the analysis, the lag lengths used in the empirical exercise were always set to 2 since $A R(2)$ models are able to capture very rich dynamics in the time series.

${ }^{14}$ Using larger values of $h$ does not change the results.
} 
Figure 3. Log likelihood and lead time of forward-looking indicators

Global PMI (new export orders

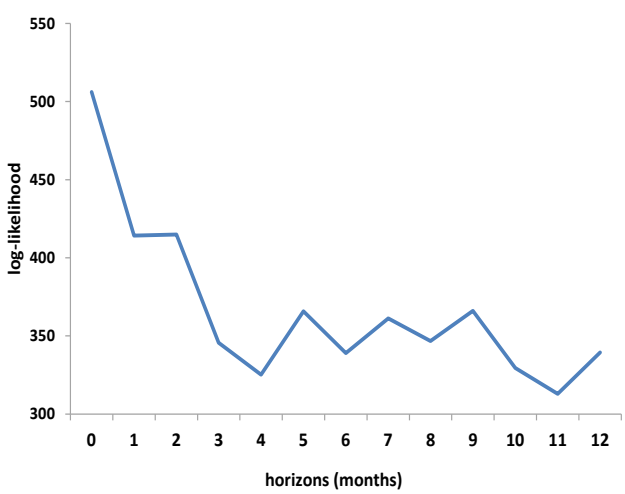

US high yield spread

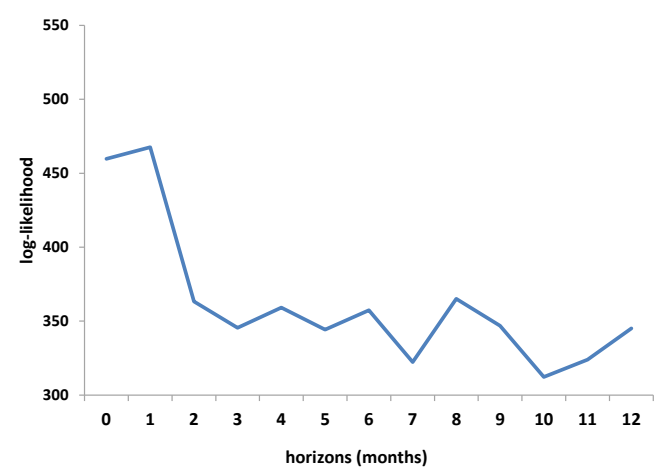

Note: US high yield spread and Markit Global PMI (New Export Orders) at time $t$ have been related to the common factor at time $t+h$. In this figure $h$ appears in the horizontal axis and the log likelihoods reached by the dynamic factor model appear in the vertical axis.

Source: Authors' calculation.

\section{Predictive accuracy: pseudo real-time analysis}

28. In the absence of real-time vintages of the selected dataset of both the monthly predictors and the quarterly growth rate of world trade, an out-of-sample analysis in pseudo real-time has been carried out to test the predictive accuracy of the WTI over the period 2012Q1-2015Q4. The method consists in computing forecasts from successive enlargements of a partition of the latest available dataset. At every iteration, after extending the dataset with one additional month of information, the model is re-estimated and the $h$ periods ahead forecasts computed. The dataset for the out-of-sample analysis starts in January 1991 and is characterised by ragged ends depending on the different data availability of the indicators. More precisely, at every period, an unbalanced dataset is reproduced in order to take into account that different asynchronous data releases have diversified predictive power on global trade growth.

29. The performance of the WTI in forecasting world trade growth is assessed against three competing forecasting models: an autoregressive model of order two $A R(2)$, which is estimated in real-time through iterative forecasts; a random walk process $R W$, whose forecasts equal the average of the latest available real-time observations; the large-scale DFM by Guichard and Rusticelli (2011).

30. A set of 9-month ahead forecasts is computed at each quarter between 2012Q1 and 2015Q4. Therefore, for each quarter of world trade growth there are 3 monthly forecasts referring to the latest missing quarter of world trade growth before its official release (backcasts), 3 monthly forecasts referring to the current quarter (nowcasts) and 3 monthly forecasts referring to the next quarter of world trade growth (forecasts). World trade growth is released on the third month of the following quarter, as a consequence the third month of the backcast prediction corresponds to the actual data.

31. Based on the root mean-squared forecast errors (RMSE) of each model, multivariate models clearly outperform univariate models. However, these gains diminish with the forecast horizon, although they remain statistically significant (Table 6). The 
intuition behind this result is that factor models use incoming information as it is available from the promptly published economic indicators. This early available information is much less valuable as the forecasting horizon increases. In fact, for large forecasting horizons, the monthly indicators are not available for the reference quarter and all the time series used in the models must be forecasted for the quarter of interest, regardless of whether the model is univariate or multivariate.

32. The pair-wise test introduced by Diebold and Mariano (1995) is used to compare pairs of models. It tests the null hypothesis of equal predictive accuracy based on differences between their RMSEs. Small- and large-scale factor models show similar predictive accuracy (Table 6), but the WTI has the advantage of being less data-consuming

Table 6. Predictive accuracy

\begin{tabular}{lccc}
\hline & Backcasts & Nowcasts & Forecasts \\
\hline Root Mean Squared Errors & & & \\
Large-scale DFM & 0.285 & 0.485 & 0.655 \\
RW & 0.611 & 0.673 & 0.691 \\
AR & 0.599 & 0.638 & 0.682 \\
WTI & 0.433 & 0.507 & 0.663 \\
Equal predictive accuracy tests & & & \\
WTI vs Large-scale DFM & 0.831 & 0.890 & 0.927 \\
WTI vs RW & 0.001 & 0.002 & 0.140 \\
WTI vs AR & 0.052 & 0.108 & 0.506 \\
\hline
\end{tabular}

Note: The forecasting sample is 2012.1-2015.4. The top panel shows the Root Mean Squared Errors (RMSE) of the large-scale dynamic factor model (Large-scale DFM) based on Guichard and Rusticelli (2011), a random walk (RW), an autoregressive model (AR), along with those of the WTI based on our extension of the DFM. The bottom panel shows the $p$-values of the Diebold-Mariano test of equal predictive accuracy.

Source: Authors' calculation.

\section{Turning points detection: dealing with non-linearities}

33. In the recent past, world trade growth has shown signs of nonlinearity, possibly due not only to major structural breaks (e.g. the latest global financial crisis), but also to the asymmetric dynamics characterising the uneven sequence of cyclical expansions and recessions. To this extent, the WTI itself is tested for the presence of a regime switch. We assume that the WTI at time $t, x_{t}$, might switch state according to an unobservable state variable $s_{t}$ that follows a first-order Markov chain. ${ }^{15}$ A simple switching model (Hamilton, 1989) can be specified as:

$x_{t}=c_{s_{t}}+\sum_{j=1}^{p} \alpha_{j} x_{t-j}+\varepsilon_{t}$

\footnotetext{
15 Camacho et al. (2015) found that although the Markov-switching dynamic factor model is generally preferred to make inferences from the common factor obtained from a linear factor model, its marginal gains rapidly diminish as the quality of the predictors used increases.
} 
The non-linear behavior of the times series is driven by the state-dependent constant $c_{s_{t}}$ which is allowed to switch between two distinct regimes $s_{t}=0$ and $s_{t}=1$. The transition probabilities are independent of the information set at $t-1, \chi_{t-1}$, and of the trade cycle states prior to $t-1$. As a result, the probabilities of staying in each state are:

$p\left(s_{t}=i \mid s_{t-1}=j, s_{t-2}=h, \ldots, \chi_{t-1}\right)=p\left(s_{t}=i \mid s_{t-1}=j\right)=p_{i j}$

where $\varepsilon_{\mathrm{t}} \sim \operatorname{iidN}\left(0, \sigma^{2}\right)$.

Table 7. Markov-switching model estimates

\begin{tabular}{ccccc}
\hline$c_{0}$ & $c_{1}$ & $\sigma^{2}$ & $p_{00}$ & $p_{11}$ \\
\cline { 2 - 5 } 1.02 & -12.29 & 11.38 & 0.99 & 0.89 \\
$(0.20)$ & $(1.05)$ & $(0.91)$ & $(0.00)$ & $(0.07)$ \\
\hline
\end{tabular}

Note: The estimated model by maximum likelihood is $x_{t}=c_{s_{t}}+\varepsilon_{t}$, where $x_{t}$ is the common factor, $s_{t}$ is a latent state variable that drives trade cycle dynamics.

Source: Authors' calculation.

34. In the state represented by $s_{t}=0$, the intercept $c_{0}$ is positive and statistically significant, while the intercept $c_{1}$ is negative in the regime referred as $s_{t}=1$ (Table 7) Hence, the first regime is labelled as world trade expansions whereas the second regime is labelled as the contraction state. Yet, according to the related business cycle literature, expansions are more persistent on average than downturns (estimated $p_{00}$ and $p_{11}$ of about 0.99 and 0.89 , respectively). This is reflected in in the average duration of expansions and contractions for the world trade growth series is 18 and 14 months, respectively (Table 8).

35. Table 8 summarizes the main results of comparing predicted probabilities of turning points and actual realisations over the sample period 1991M1 - 2017M7. The dates of turning points for the single-index and the quarterly world trade growth series (monthly basis) are given by applying the Bry and Boschan (1971) algorithm, which indicates peaks and troughs charactering the world trade series following the NBER turning points detection method. These results show that the WTI is in striking accord with the quarterly world trade series, with an average lag of one month and maximum lead of two. 
Table 8. Trade cycle accuracy: turning points detection

\begin{tabular}{|c|c|c|c|c|c|c|}
\hline & \multicolumn{2}{|c|}{ World trade series } & \multicolumn{2}{|c|}{ World Trade Index } & \multicolumn{2}{|c|}{ Accuracy } \\
\hline & Through & Peak & Through & Peak & Through & Peak \\
\hline & & & & Mar.1992 & & \\
\hline & Nov. 1992 & Jun. 1994 & Nov. 1992 & Dec. 1994 & $=$ & -5 \\
\hline & Jul. 1995 & Aug. 1997 & Nov. 1995 & Jun. 1997 & & 2 \\
\hline & Nov. 1998 & Nov. 1999 & Nov. 1998 & Nov. 1999 & $=$ & $=$ \\
\hline & Oct. 2001 & Apr. 2002 & Oct. 2001 & Jul. 2002 & $=$ & -3 \\
\hline & May 2003 & Dec. 2003 & Jun. 2003 & Jan. 2004 & -1 & -1 \\
\hline & Mar. 2005 & Jan. 2006 & Mar. 2005 & Feb. 2006 & $=$ & -1 \\
\hline & Sep. 2006 & May. 2007 & Sep. 2006 & Nov. 2008 & $=$ & \\
\hline & Dec. 2008 & Sep. 2009 & Mar. 2009 & & -3 & \\
\hline & Jul. 2012 & Nov. 2013 & . & Feb. 2014. & & -3 \\
\hline & Mar. 2016 & Jan. 2017 & Mar. 2016 & . & $=$ & \\
\hline Avg. duration of contractions & \multicolumn{2}{|c|}{14.2} & \multicolumn{2}{|c|}{17.1} & & \\
\hline Avg. duration of expansions & \multicolumn{2}{|c|}{18.3} & \multicolumn{2}{|c|}{12.3} & & \\
\hline Avg. amplitude of contractions & \multicolumn{2}{|c|}{-4.0} & \multicolumn{2}{|c|}{-10.2} & & \\
\hline Avg. amplitude of expansions & \multicolumn{2}{|c|}{3.7} & \multicolumn{2}{|c|}{11.2} & & \\
\hline
\end{tabular}

Note : Min. phase $=5 ;$ Min. cycle: $15 ;$ Symmetric window $=15 ;$ Threshold parameter $=25$. Positive signs in accuracy refer to leads and negative to lags.

Source: Authors' calculation.

36. Additionally, to assess whether the WTI also performs well at predicting turning points, the forecasting quadratic probability score (FQPS) is computed as:

$F Q P S=1 / T \sum_{t=1}^{T} 2\left(\Pi_{t}-R_{t}\right)^{2}$

where $\Pi_{t}$ is the time-t probability forecast of a turning point over the horizon $h$, and $R_{t}$ equals one if a turning point (peak or through) occurs within the horizon (i.e., between times $t$ and $t+h$ ) and equals zero otherwise. ${ }^{16}$

37. More precisely, FQPS is defined as the mean squared deviation of the probabilities of trade contractions from a recessionary indicator that takes the value of one in the periods dated as world trade contractions by the Bry and Boschan (1971) algorithm and zeroes elsewhere. The FQPS ranges from 0 to 2 , with a score of 0 corresponding to perfect accuracy. The obtained value of $F Q P S=0.21$ indicates that the WTI performs relatively well at predicting turning points. This is confirmed by the high correlation between the probability of contraction as indicated by the WTI and actual world growth contractions (Figure 4). ${ }^{17}$

\footnotetext{
${ }^{16}$ It is the only proper scoring rule that is a function of the divergence between predictions and realizations. For further details, see Brier (1950) and Diebold and Rudebusch (1996).

${ }^{17}$ It is worth noting that, given the larger cyclicality of merchandise trade with respect to service trade, detected turning points inferring the state of the world trade cycle are more likely associated with global movements in merchandise trade.
} 
Figure 4. Probabilities of world trade growth contractions from the WTI

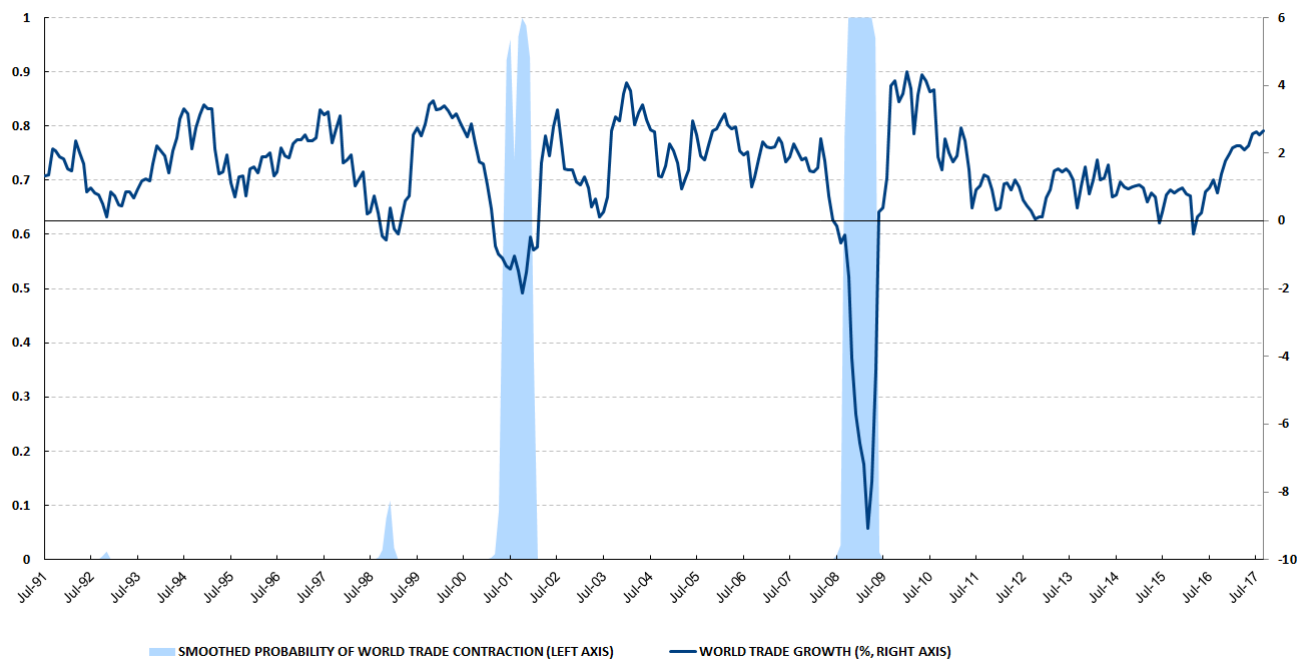

Note: Shaded areas refer to (monthly) probabilities of a global trade contraction from the WTI, in-sample estimation over 1991-2016. World trade growth refers to the quarterly growth rate on a monthly basis. Source: Authors' calculations.

\section{Conclusions}

38. It is a challenge to construct practical and satisfactory tools to monitor global trade cycles due to the lags in publishing historical data. This paper proposes a small-scale dynamic factor model with leading indicators under a mixed frequencies framework to monitor global trade growth in real time and to produce accurate backcasts, nowcasts and 1-period ahead forecasts. The indicators used in the DFM are selected by means of model averaging techniques, dynamic correlations and Granger non-causality predictability tests. The resulting World Trade Index (WTI) is used to predict global trade growth and to capture trade cycle turning points. The findings suggest that the model is successful in computing a coincident indicator, which is able to explain a high percentage of the variance of actual trade growth. In addition, empirical simulations suggest that global credit and trade finance conditions have led the global trade cycle by at least one month on average over the past years. Finally, pseudo real-time analysis shows that the WTI outperforms a number of competing models, making it useful for trade cycle monitoring, nowcasting and short-term forecasting of global trade growth. 


\section{REFERENCES}

Aruoba B, and F. Diebold (2010). "Real-time macroeconomic monitoring: Real activity, inflation, and interactions. American Economic Review: Papers \& Proceedings, 100: 20-24.

Barhoumi, K., Darné, O., and L. Ferrara (2016), "A World Trade Leading Index (WTLI)", Economic Letters 146, pp. 111-115.

Baldwin, R. (2009), "The great trade collapse: What caused it and what does it mean?", VoxEU, Nov 27.

Boivin, J., and S. Ng (2006) “Are more data always better for factor analysis?”, Journal of Econometrics 132, pp. 169-194.

Bry, G. and C. Boschan (1971) "Cyclical Analysis of Time Series: Procedures and Computer Programs", New York, NBER.

Burgert, M., S. Dees. (2008) "Forecasting World Trade: Direct versus Bottom-Up Approaches", European Central Bank Working Paper No 882.

Bussiére, M., Callegari, G., Ghironi, F., Sestieri, G., and N. Yamano (2013), "Estimating trade elasticities: Demand composition and the trade collapse of 2008-2009". American Economic Journal: Macroeconomics, American Economic Association, 5(3): 118-151.

Brier. G. W. (1950), "Verification Forecasts Expressed in terms of Probability", Monthly Weather Review, 75, pp. 1-3.Camacho, M. and G. Pérez Quirós (2010), "Introducing the Euro-STING: Short Term Indicator of euro area Growth", Journal of Applied Econometrics 25: 663-694.

Camacho, M., and J. Martinez-Martin (2014), "Real-time forecasting US GDP from smallscale factor models", Empirical Economics, 49(1), pp. 347-364.

Camacho, M., Perez Quiros, G., Poncela, P. (2015) "Extracting nonlinear signals from several economic indicators", Journal of Applied Econometrics (30), pp. 1073-1089.

Croux, C., Forni, M., and L. Reichlin. (2001) "A measure of comovement for economic variables: theory and empirics", Review of Economic Statistics, 94(4), pp. 1014-1024.

Diebold, F., and R. Mariano (1995) "Comparing predictive accuracy". Journal of Business Economic Statistics 13: 253-263.

Diebold, F., and Rudebusch, G. (1996) "Measuring business cycles: A modern perspective". Review of Economics and Statistics 75: 67-77.

Dolado, J.J., and H. Lütkepohl. (1996), "Making Wald tests work for cointegrated VAR systems", Econometrics Reviews 15, 369-386.

Guichard, S., and E. Rusticelli. (2011) "A dynamic factor model for world trade growth". OECD Economics Department Working Papers, 874.

Golinelli, R., and Parigi, G. (2013) "Tracking world trade and GDP in real time". Banca d'Italia Working Papers, $\mathrm{N}^{\circ} 920$.

Gregory, A.W., Head, A.C., and J. Reynauld (1997) "Measuring world business cycles". International Economic Review, 38: 677-701. 
Hamilton, J. (1989), "A new approach to the economic analysis of nonstationary time series and the business cycles", Econometrica, Vol. 57. pp. 357-384.

Hamilton, J. (2011), "Calling recessions in real time". International Journal of Forecasting 27: 1006-1026.

Hoeting, J.A., Madigan, D., Raftery, A.E. \& Volinsky, C.T. (1999), "Bayesian model averaging: A tutorial", Statistical Science, (14): 382- 417.

Inoue, A., and L. Kilian (2004), "In-sample or out-of-sample tests of predictability: which one should we use?", Econometrics Reviews (23): 371-402.

Jakaitiene, A., and S. Dees (2012), "Forecasting the World Economy in the Short Term", The World Economy, Vol. 35(3), pp. 331-350.

Martins, J., and S. Araujo (2009), "The Great Synchronisation: tracking the trade collapse with high-frequency data", VoxEU, Nov 27.

Mariano, R.S., and Y. Murasawa (2003), "A new coincident index of business cycles based on monthly and quarterly series", Journal of Applied Econometrics, Vol. 18, pp. 427-43 .

Moral-Benito, E. (2015), "Model averaging in economics: An overview". Journal of Economic Surveys, (29): 46-75.

Stock, J.H., and M. Watson (1991), "A Probability Model of the Coincident Economic Indicators", in K. Lahiri and G. Moore (Eds.), Leading Economic Indicators: New Approaches and Forecasting Records, Cambridge University Press, UK, pp. 63-89.

Stock, J.H., and M. Watson (2002), "Macroeconomic forecasting using diffusion indexes" Journal of Business and Economic Statistics 20: 147-162.

Stratford, K. (2013), "Nowcasting world GDP and trade using global indicators". Bank of England Quarterly Bulletin, 2013Q3.

Timmer, M. P., Los B., Stehrer, R., and G.J. de Vries (2016), "An Anatomy of the Global Trade Slowdown based on the WIOD 2016 Release", GGDC Research Memorandum N. 162.

World Trade Organization (2016), "World Trade Outlook Indicator (WTOI)", WTO Methodological note available at: https://www.wto.org 


\section{Annex A. State space representation and mixing data frequencies}

\section{State-space representation and estimation}

For the sake of simplicity, assume that only one quarterly (world trade) indicator $g_{t}$, one monthly coincident indicator $z_{i t}$, and one monthly leading indicator $z_{l t}$, are all collected in the vector $Y_{t}=\left(g_{t}, z_{i t}, z_{l t}\right)^{\prime}$. Supposing that the autoregressive orders $p 1=p 2=p 3=1$ and that the lead of the leading indicator is $h=1$, the measurement equation, $Y_{t}=H \xi_{t}+E_{t}$, with $E_{t} \sim \operatorname{iidN}(0, R)$, can be stated as:

$Y_{t}=\left(g_{t}, z_{i t}, z_{l t}\right)$,

$H=\left(\begin{array}{ccccccccccccc}0 & \frac{\beta_{y}}{3} & \frac{2 \beta_{g}}{3} & \beta_{g} & \frac{2 \beta_{g}}{3} & \frac{\beta_{g}}{3} & \frac{1}{3} & \frac{2}{3} & 1 & \frac{2}{3} & \frac{1}{3} & 0 & 0 \\ 0 & \beta_{i} & 0 & 0 & 0 & 0 & 0 & 0 & 0 & 0 & 0 & 1 & 0 \\ \beta_{l} & 0 & 0 & 0 & 0 & 0 & 0 & 0 & 0 & 0 & 0 & 0 & 1\end{array}\right)$,

$\xi_{t}=\left(x_{t+1}, x_{t}, x_{t-1}, x_{t+2}, x_{t+3}, x_{t+4}, u_{t}^{g}, u_{t-1}^{g}, u_{t-2}^{g}, u_{t-3}^{g}, u_{t-4}^{g}, u_{t}^{i}, u_{t}^{l}\right)^{\prime}$.

The model assumes a contemporaneous correlation between non-leading indicators and the trade cycle, whereas for leading indicators the correlation is imposed between the current values of the indicators and future values of the common factor.

In the same way, the transition equation, $\xi_{t}=F \xi_{t-1}+W_{t}$, with $W_{t} \sim \operatorname{iid} N(0, Q)$, can be stated as:

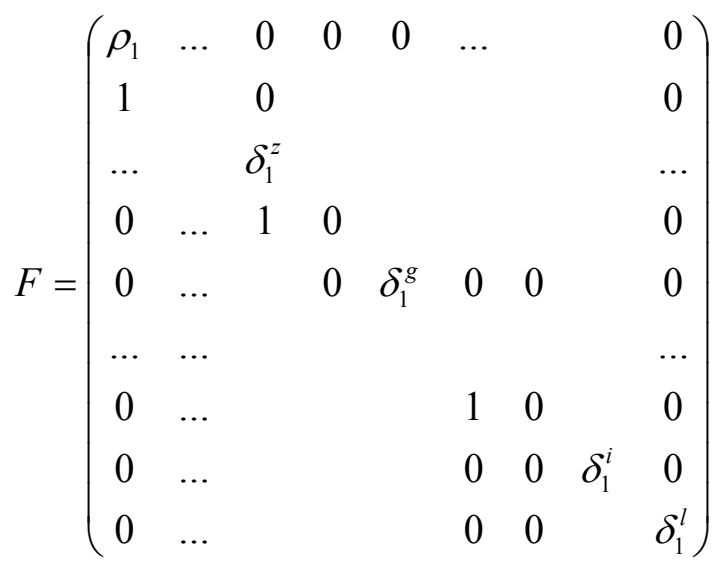

where $Q=\operatorname{diag}\left(\sigma_{\varepsilon}^{2}, 0, \ldots, 0, \sigma_{g}^{2}, 0, \ldots, \sigma_{i}^{2}, \sigma_{l}^{2}\right) .18$

It is assumed that the measurement equation errors are independent of the transition equation errors.

18 The identifying assumption implies that the variance of the common factor is normalised to a value of one, which is a standard assumption in factor models. 
If all series were observable at the monthly frequency, the estimation of the model could be performed by standard maximum likelihood using the Kalman filter. However, other techniques are needed when time series of different length and different reporting lags are used and in particular when monthly data are mixed with quarterly data.

In order to handle mixed frequency and ragged ends datasets, Mariano and Murasawa (2003) treat the unavailable current data as missing observations by replacing them with random draws $\vartheta_{t}$ and applying the maximum likelihood estimation of a linear Gaussian state-space model with missing observations. ${ }^{19}$

Thus, the likelihood function of the observed data and that of the data whose missing values are replaced by the random draws are equivalent up to scale.

Let $Y_{i t}$ be the $i$-th element of the vector $Y_{t}$ and $R_{i i}$ be its variance. Let $H_{i}$ be the $i$-th row of the matrix $H$ which has $\varsigma$ columns and let $0_{1 \varsigma}$ be a row vector of $\varsigma$ zeroes. The measurement equation can be replaced by the following expressions:

$$
\begin{aligned}
& Y_{i t}^{+}=\begin{array}{rrr}
Y_{i t} & \text { if } Y_{i t} \text { is observable } \\
\vartheta_{t} & \text { otherwise }
\end{array} H_{i t}^{+}=\begin{array}{rr}
H_{i t} & \text { if } Y_{\text {it }} \text { is observable } \\
0_{1 \varsigma} & \text { otherwise }
\end{array} \\
& E_{i t}^{+}=\begin{array}{lr}
0 & \text { if } Y_{i t} \text { is observable } \\
\vartheta_{t} & \text { otherwise }
\end{array} \quad R_{i t}^{+}=\begin{array}{lr}
0 & \text { if } Y_{\text {it }} \text { is observable } \\
\sigma_{\varrho}^{2} & \text { otherwise }
\end{array}
\end{aligned}
$$

According to this transformation, the time-varying state space model can be treated as having no missing observations so the Kalman filter can be directly applied to $Y_{t}^{+}, H_{t}^{+}$, $E_{t}^{+}$, and $R_{t}^{+}$.

The estimation of the model parameters can be developed by numerically maximizing the $\log$-likelihood of $\left\{Y_{t}^{+}\right\}_{t=1}^{t=T}$ with respect to the unknown parameters. Let $\xi_{t / \tau}$ be the estimate of $\xi_{t}$ based on information up to period $\tau$. Let $P_{t / \tau}$ be its covariance matrix. The prediction equations are:

$$
\begin{aligned}
& \xi_{t / t-1}=F \xi_{t-1 / t-1} \\
& P_{t / t-1}=F P_{t-1 / t-1} F^{\prime}+Q
\end{aligned}
$$

Hence, the predicted value of $Y_{t}$ with information up to $t-1$, denoted by $Y_{t / t-1}$ is:

$$
Y_{t / t-1}=H^{+} \xi_{t / t-1}
$$

and the prediction error is:

$$
\eta_{t / t-1}=Y_{t}^{+}-Y_{t-1}=Y_{t}^{+}-H \xi_{t / t-1}
$$

\footnotetext{
${ }^{19}$ Replacements by constants would also be valid. It is assumed that the random draws come from independent from the parameter space characterising the Kalman filter.
} 
with covariance matrix:

$v_{t / t-1}=H^{+} P_{t / t-1} H^{+}+R_{t}^{+}$

The way missing observations are treated implies that the filter, through its implicit signal extraction process, will put no weight on missing observations in the computation of the factors. In each iteration, the log-likelihood can be computed as:

$\log L_{t / t-1}=-\frac{1}{2} \ln \left(2 \pi\left|v_{t / t-1}\right|\right)-\frac{1}{2} \eta_{t / t-1}^{\prime}\left(v_{t / t-1}\right)^{-1} \eta_{t / t-1}$

It is worth noting that the transformed filter to handle missing observations has no impact on the model estimation. In that sense, the missing observations simply add a constant to the likelihood function of the Kalman filter process. Hence, the parameters that maximize the likelihood are achieved as if all the variables were observed.

The updating equations are:

$$
\begin{aligned}
& \xi_{t / t}=\xi_{t / t-1}+P_{t / t-1} H_{t}^{+}\left(v_{t / t-1}\right)^{-1} \eta_{t / t-1} \\
& P_{t / t}=P_{t / t-1}+P_{t / t-1} H_{t}^{+}\left(v_{t / t-1}\right)^{-1} H_{t}^{+} P_{t / t-1}
\end{aligned}
$$

Therefore, missing observations are skipped from the updating recursion. 


\section{Annex B. Mixing frequencies}

The model is illustrated using a single low-frequency variable, sampled at the quarterly frequency, and a single high-frequency variable, sampled at the monthly frequency. In order to be combined in the same model, quarterly data are treated as a monthly series with missing observations. In this case, the quarterly series is assumed to be observed in the last month of the quarter and exhibit missing observations in the first two months of each quarter.

In particular, let $G_{t}$ be the level of a quarterly flow variable that can be decomposed as the sum of three (usually unobserved) monthly values $G_{t}^{*}$.To avoid using a more complicated non-linear state-space model, and approximate the arithmetic mean is approximated by the geometric mean as in Mariano and Murasawa (2003). Hence, the level of the variable can be written as:

$$
G_{t}=3\left(G_{t}^{*} G_{t-1}^{*} G_{t-2}^{*}\right)^{1 / 3}
$$

Taking logs on both sides of this expression and computing the three-period differences for all $t$, the following identity is obtained:

$$
\Delta_{3} \ln G_{t}=\frac{1}{3}\left(\Delta_{3} \ln G_{t}^{*}+\Delta_{3} \ln G_{t-1}^{*}+\Delta_{3} \ln G_{t-2}^{*}\right)
$$

Denoting the quarterly growth rate as $\Delta_{3} \ln G_{t}=g_{t}$ and the monthly growth rate as $\Delta \ln G_{t}^{*}=g_{t}^{*}$, it follows:

$$
g_{t}=\frac{1}{3} g_{t}^{*}+\frac{2}{3} g_{t-1}^{*}+g_{t-2}^{*}+\frac{2}{3} g_{t-3}^{*}+\frac{1}{3} g_{t-4}^{*}
$$

Hence, the quarterly growth rate $g_{t}$ is expressed as a weighted average of the past monthly growth rates $g_{t-i}^{*}$ of the monthly series with $i=0, \ldots, 4$. 